\title{
Coronary revascularization in robotic cardiac surgery
}

\author{
Burak Onan (D) \\ Department of Cardiovascular Surgery, University of Health Sciences, Istanbul Mehmet Akif Ersoy Thoracic and Cardiovascular Surgery Training and Research Hospital, Istanbul, Turkey
}

Received: April 19, 2017 Accepted: February 14, 2018 Published online: April 24, 2019

\section{ABSTRACT}

Robotic surgery has evolved worldwide after 2000s. In cardiac surgery, totally endoscopic robotic endoscopic surgery has been frequently performed in mitral/tricuspid valve pathologies, atrial septal defects, coronary revascularization, and intracardiac tumors. In this review, we discuss robotic approach to coronary revascularization and surgical technique in patients with ischemic heart disease in the light of literature data.

Keywords: Coronary revascularization, ischemic heart disease, robotic surgery.

In recent years, robotic surgical technologies and techniques have developed rapidly throughout the world and have taken their place in different branches. In the literature, robotic surgery was first described in the field of gynecology and obstetrics, followed by urology. ${ }^{[1-7]}$ In the late 1990s, cardiac surgeons paid an interest and began to use the robotic systems. ${ }^{[1-7]}$ Developments in endoscopic imaging technologies, the construction of small diameter instruments, and improvements in peripheral cannulation devices and applications have enabled the use of robotic surgery in cardiac surgeries. All these developments through special surgical trainings and clinical programs have made the use of robotic systems in cardiac surgery widespread. In the beginning of the 2000s, left internal thoracic artery harvesting for roboticassisted coronary revascularization operations and total endoscopic mitral valve operations have been successfully performed in increasing numbers around the world with the widespread use of the da Vinci telemanipulation system. ${ }^{[8-13]}$

The first use of endoscopic systems dates back to the early 1980s (Table 1). ${ }^{[10]}$ Since then, systems can be classified into two main groups including prototypes and improved systems. Prototypes were first used in 1983. The first orthopedic operation (arthroscopy) was performed in the history of medicine with the Arthrobot (Vancouver, BC, Canada), which is considered the first surgical robot. Then, in 1985, the first brain biopsy was performed with the
Unimation Puma 200 (Unimation; manufacturer defunct) device under the guidance of computed tomography. ${ }^{[14]}$ In 1992, the first fully closed robotic surgical practice (prostate surgery) in the world using the Probot (Imperial College, London, UK) was performed at St. Thomas hospital. ${ }^{[15]}$ The use of these devices has revolutionized the surgical practice and a new era of robotic surgery has been introduced. With the advances in technology and increased interest in endoscopic surgical techniques, a rapid progress to current techniques has been achieved.

The first period in which prototypes were used followed the second period, in which advanced surgical systems were used. This period extended from the 1990s to the present day. Initially, two main systems were used between 1990 and 2000. The latter, Aesop Hermes-ready (Computer Motion Inc., Santa Barbara, CA, USA) system, was introduced in 1994. ${ }^{[15]}$ This system can be described as a camera system which is moved or guided by vocal command. With the vocal commands of the surgeon, the camera holder could move in the desired and programmed direction, while

Corresponding author: Burak Onan, MD. SBÜ İstanbul Mehmet Akif Ersoy Göğüs ve Kalp Damar Cerrahisi Eğitim ve Araştırma Hastanesi Kalp ve Damar Cerrahisi Kliniği, 34303 Küçükçekmece, İstanbul, Turkey.

Tel: +90 553-622 3878 e-mail: burakonan@hotmail.com

\section{Citation:}

Onan B. Coronary revascularization in robotic cardiac surgery. Cardiovasc Surg Int 2018;5(1):12-23. 


\begin{tabular}{|c|c|}
\hline \multicolumn{2}{|c|}{$\begin{array}{c}\text { Table } 1 \\
\text { Chronological background of robotic endoscopic surgical systems }\end{array}$} \\
\hline & The development of surgical endoscopic systems \\
\hline \multicolumn{2}{|l|}{ Prototypes } \\
\hline 1983, the first surgical robot, 'Arthrobot' & Orthopedy operation-arthroscopy, \\
\hline 1985, the Unimation “Puma 200” & Computed-tomography guided first robotic cerebral biopsy \\
\hline 1992, “the PROBOT” & The first totally endoscopic robotic surgery in the world-prostate surgery \\
\hline \multicolumn{2}{|l|}{ Advanced systems } \\
\hline 1994, Aesop Hermes-ready system & Computer motion \\
\hline 1998, Zeus system & $\begin{array}{l}\text { Computer motion, } \\
* \text { the first coronary bypass in } 1998\end{array}$ \\
\hline 1996, da Vinci system (intuitive surgical) & $\begin{array}{l}\text { Telemanipulation system, } \\
\text { * the first robotic case was mitral valve repair in } 1996 \\
\text { * the first minimally invasive direct coronary artery bypass in } 1999\end{array}$ \\
\hline
\end{tabular}

the surgeon was performing surgery with the help of an endoscopic screen. This system was followed by the Zeus (Computer Motion Inc., Santa Barbara, CA, USA) surgical system. ${ }^{[15]}$ In this system, a stereotactic screen was added to the previous system, allowing the surgeon to apply endoscopic surgery using both the camera and right and left arm using a special screen and vocal command system. However, the difficulties and limitations of the use of these systems prevented them from becoming widespread. The era of the Aesop and Zeus systems ended with the use of the da Vinci telemanipulation system, which is a more sophisticated surgical technology.

The first robot-assisted cardiac operation with the da Vinci surgical endoscopic system was performed in 1996 using the prototype of this system, and it was a mitral valve repair operation performed by Carpentier et al. ${ }^{[4]}$ This operation was followed by Mohr et al. ${ }^{[5]}$ and, later in the same year, Loulmet et al. ${ }^{[2]}$ performed minimally invasive direct coronary artery bypass (MIDCAB) graft surgeries. Minimally invasive techniques, however, have begun to be used in hybrid surgical interventions. The first emergence of hybrid interventions was in the late 1990s. Hybrid applications in cardiac surgery were first introduced by Benetti and Ballester in 1995. ${ }^{[6]}$ The first thoracoscopic left internal thoracic artery (ITA) removal and endoscopic minimally invasive single-vessel coronary artery bypass grafting (CABG) were successfully performed in two patients by Dr. Benetti. ${ }^{[6]}$ Subsequently, in 1996 and 1999, robot-assisted minimally invasive myocardial revascularization procedures were performed in multivessel disease. ${ }^{[2,7]}$ Since then, minimally invasive and robotic surgical techniques and cardiac catheterization procedures have been used more frequently. ${ }^{[8]}$

In Turkey, the first robotic heart surgery program was initiated at Florence Nightingale Hospital in Istanbul, Turkey under the leadership of Prof. Belhhan Akpinar, MD. This program is also the first robotic endoscopic surgery program in Turkey. Prof. Akpinar and Prof. Ertan Sagbas and Prof. Mustafa Guden from his team performed the first successful robotic coronary bypass series in our country and long-term outcomes have recently been published. ${ }^{[16-18]}$ In addition, the mitral valve and atrial septal defect operations were successfully performed with the first three-arm version of the da Vinci system. This team has the largest series of robotic cases in Turkey. Successful results of this surgery team succeeded by Prof. Cem Alhan's robotic program and successful results have been reported recently. ${ }^{[19,20]}$ The robotic surgery program, which was initiated by our team in May 2013 by Prof. Ihsan Bakir and currently carried out by our team, is one of the largest series in Turkey. Until now, more than 350 robotic total endoscopic heart surgeries and more than 100 robotic MIDCAB cases were successfully performed in our center. ${ }^{[21-26]}$ All of these operations have allowed our country to be among the top five countries in the world and to be among one of the first in Europe, in the field of robotic cardiac surgeries (Data from Cordamed Inc., Istanbul, Turkey, 2016). This success is extremely important for the medical literature in Turkish and surgical success of Turkey. 


\section{ADVANTAGES OF ROBOTIC SURGERY}

For minimally invasive cardiac surgical interventions, the main goal is to minimize trauma to the patients with lower postoperative morbidity and mortality rates for high-risk patients for surgery. ${ }^{[27]}$ We can divide the advantages of the robotic surgery in two main groups: technical and clinical. Among the technical advantages, the main feature distinguishing robotic surgery from other endoscopic surgical procedures is that the maximum image area is three-dimensional which allows the surgeon to apply surgical techniques comfortably and safely on the endoscopic imaging console. In addition, the robot's instrument arms work synchronously with the right and left arm movements of the surgeon. Port diameters are small $(8.12 \mathrm{~mm})$ and surgical incisions are small accordingly. All of these offer the patient with the least invasive surgical procedure. The major clinical advantages of robotic surgery are as follows:

- No sternotomy or wide thoracotomy incisions

- Less systemic inflammatory response

- Avoidance or minimization of cardiopulmonary bypass (CPB), cardiac arrest, and aortic manipulation

- Absent or minimal bleeding/use of blood products

- Less postoperative pain and early mobilization

- Rapid postoperative healing period

- Shortened hospital stay

- Sooner return to daily living activities or work

- Improved cosmetic results

- Postoperative psychological advantages, such as self-confidence

\section{DISADVANTAGES OF ROBOTIC SURGERY}

Besides all these advantages, there are some disadvantages including longer operating times, the need for a specific learning curve, technical details and know-how, endoscopic surgical experience, and the absence of sensory recall on the console during surgery called the haptic feedback. More importantly, the high cost of the device and low number of centers where the devices are available cannot be neglected.

\section{FEATURES OF ROBOTIC da VINCI SYSTEM}

The only endoscopic surgical system currently in use without any alternative is the da Vinci system. Features of this system include three-dimensional (3D) and advanced resolution (1080i) imaging, advanced sensitivity, 270-degree wrist motion, spatial orientation, haptic feedback, training programs and simulation. This system mainly consists of two main units (Figure 1). First unit is the surgeon console which provides the surgeon to operate in an endoscopic 3D simulator. The surgeon sees the operation area with a high-resolution, high-performance imaging system. The second unit is the patient console which allows robotic instruments to be fixed in the thoracic cavity and to simulate appropriate movement. Robotic arms and instruments placed in the thorax are easily used via successful simulation of the hand movements of the surgeon and active wrist movement. There are different instruments in robotic surgery for harvesting the internal thoracic artery. These include micro-spatula, micro-forceps, mini-clip applicators, endoscopic heart stabilizers, porte
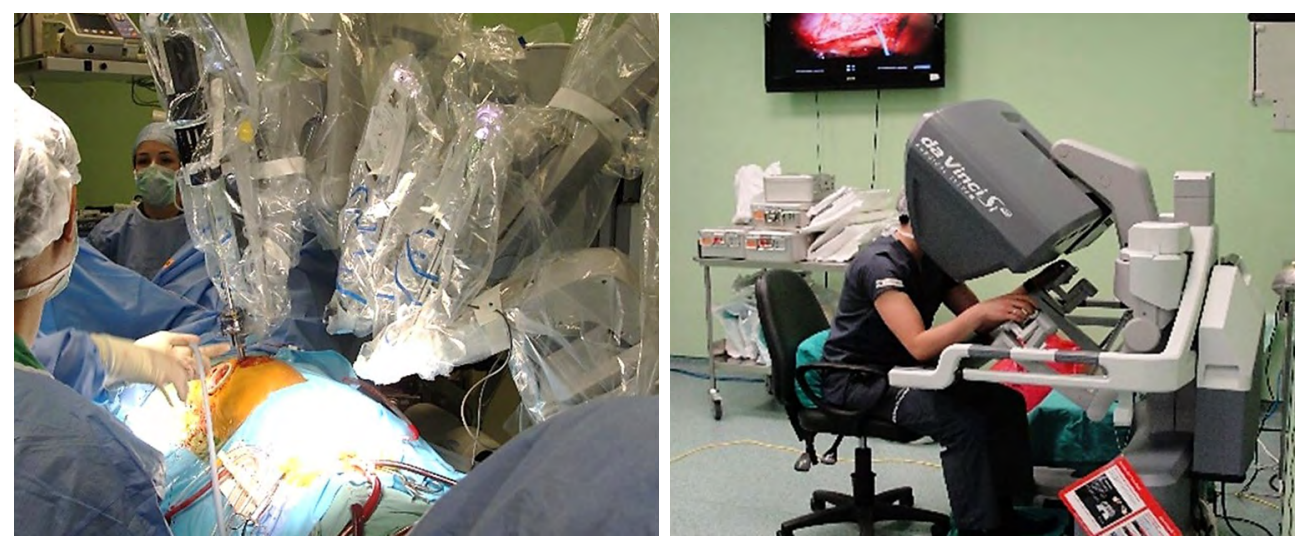

Figure 1. Surgeon console and patient bedside unit of the da Vinci system. 


\begin{tabular}{|c|c|}
\hline & $\begin{array}{l}\text { Table } 2 \\
\text { Robotic cardiac surgical procedures }\end{array}$ \\
\hline Procedures & Details \\
\hline Coronary artery bypass grafting & $\begin{array}{l}\text { Robotically-assisted minimally invasive direct coronary artery bypass } \\
\text { Totally endoscopic coronary artery bypass }\end{array}$ \\
\hline Mitral valve repair or replacement & $\begin{array}{l}\text { Resection versus non-resection repair techniques } \\
\text { Biological and mechanical valve replacement }\end{array}$ \\
\hline Atrial septal defect closure & $\begin{array}{l}\text { Primary closure of secundum type defects } \\
\text { Patch closure of all types of atrial septal defects including coronary sinus type defects }\end{array}$ \\
\hline Ablation for atrial fibrillation & Radiofrequency ablation or cryoablation procedures \\
\hline Anomalous partial pulmonary venous return & Right upper pulmonary veins to the superior vena cava or right atrium \\
\hline Left atrial appendage closure & With mitral valve surgery \\
\hline Partial atrioventricular septal defects & Primum septal defect and mitral cleft closures \\
\hline Intracardiac tumor resection & $\begin{array}{l}\text { Right or left atrial and left ventricular myxomas } \\
\text { Fibroelastoma of the mitral valve }\end{array}$ \\
\hline Left ventricular pacemaker lead implantation & Arrhythmia surgery \\
\hline
\end{tabular}

aiguille (needle holder), potts scissors, and retractors. Depending on the process to be done, some of these tools can be selected. Frequently performed robotic surgical interventions include robot-assisted CABG with total endoscopic or mini-thoracotomy, mitral valve repair or replacement, closure of atrial septal defects, radiofrequency or cryoablation procedures in the treatment of atrial fibrillation, resection of some cardiac tumors, and left ventricular epicardial pacemaker implantation (Table 2).

\section{INDICATIONS AND \\ CONTRAINDICATIONS FOR ROBOTIC CABG}

There is no absolute contraindication for minimally invasive cardiac operations. ${ }^{[27]}$ All patients are candidates for a minimally invasive procedure.
However, every patient should be examined in detail and the priority should be not to harm the patient during the intervention. The clinical status of the patients, associated morbidities, and anatomical features should be also evaluated well. Patient selection in robotic surgery is extremely important in terms of indications as much as the intervention itself. All interventions may not be appropriate for every patient.

Robotic CABG is commonly used in total occlusion or osteal stenosis of the left anterior descending artery (LAD). ${ }^{[9,11,16,17]}$ It may be applied occasionally in proximal LAD stenosis, which is not suitable for percutaneous intervention. In addition, although less frequently, it can be used for the treatment of multivessel disease. In these patients, both ITAs and a second graft can be used individually or with sequential anastomosis techniques, although these interventions

$\begin{array}{ll} & \text { Table } 3 \\ & \text { Patient selection } \\ \text { Ideal patient's characteristics for robotic surgery }\end{array}$


are rarely applied in daily use. In addition, hybrid therapy may be an appropriate approach in some patient groups. ${ }^{[9,11]}$ In hybrid procedures, stenting is usually performed with percutaneous technique in the right coronary or circumflex coronary arteries in the presence of severe stenosis or occlusion of the LAD artery. Left ITA-LAD artery anastomosis can be, then, performed by robotic methods. Of note, hybrid approaches can be used to reduce the morbidity and mortality of open heart operations.

\section{PATIENT SELECTION}

Surgical approach is decided before surgery according to the patients' history and physical examination. ${ }^{[27]}$ The features which should be considered during patient selection are presented in Table 3. Possible complications can be prevented in this way. Cardiac surgical procedures are usually performed in older patients and lung, kidney, and cerebral diseases are common in this population. Avoidance of $\mathrm{CPB}$ or minimization of surgical incision in coronary artery disease can prevent organ dysfunction. ${ }^{[28,29]}$ In addition, it has been shown that reducing inflammatory response provides protection of heart, lung, and kidney function. Minimally invasive approach and incisions are associated with less postoperative pain. ${ }^{[26,30,31]}$ This provides more comfort for patients during coughing, the removal of secretions, and functional rehabilitation of the lungs.

Pleural pathologies are relative contraindications for robotic interventions. While mild and local adhesions do not cause much problems in endoscopic procedures, it is more appropriate to perform the operation with conventional techniques in the presence of severe adhesions and calcifications. Preoperative diagnosis of adhesions in the left pleura can be difficult and thoracic $\mathrm{X}$-ray or computed tomography can be more helpful to predict adhesions and pleural thickening in severe lung pathologies, while mild pleural thickening and adhesions are difficult to be diagnosed preoperatively. Surgery and vision can be impaired in emphysematous pulmonary disease. Previous pericarditis can complicate the application of the surgical technique. In reoperation cases, MIDCAB and totally endoscopic coronary artery bypass grafting (TECAB) procedures are not preferred. Emphysematous changes and pleural thickening, retractions or calcifications are among the relatively contraindications in minimally invasive procedures.
In addition to associated morbidities, anatomical features are also important for a minimally invasive procedure. The height and weight of the patient and thoracic structure should be evaluated during physical examination in the preoperative period. Shorter patients with a short diameter of anteroposterior and upperlower should be carefully examined for minimally invasive surgical techniques. Excessively obese patients (body mass index over $30 \mathrm{~kg} / \mathrm{m}^{2}$ ) should be meticulously evaluated. In female patients, the dimensions of the breast tissue may create difficulties during the port placement. In addition, the diaphragm height may impair the vision and access to the heart from the left thorax. In such cases, the left arm instruments and stabilizers cannot be placed from the fifth or sixth intercostal space for robotic surgical set-up.

Cardiopulmonary bypass may be required for MIDCAB and TECAB procedures in minimally invasive cardiac surgery. Therefore, it is of utmost importance to evaluate the aorta and iliofemoral arteries during preoperative angiography. Peripheral cannulation is often used for CPB. Patients with advanced age, diabetes, hypertension, and peripheral vascular disease should undergo preoperative physical examination and vascular imaging. Evaluation of the peripheral vascular structures for $\mathrm{CPB}$ prevents possible complications such as vascular laceration, rupture, or dissection.

\section{ANESTHETIC APPROACH}

Patients are operated under general anesthesia and double-lumen intubation. ${ }^{[32,33]}$ In addition, single lumen intubation can be used safely, particularly during robotic-assisted CABG. The cessation of the left pulmonary ventilation during removal of the left and right ITA is particularly important during the placement of robotic instruments and postoperative bleeding control. Radial artery and central venous catheterization is usually performed in the preparation stage of the operation. External defibrillation pads are routinely used. One of the pads is placed on the lateral wall of the right thorax and the other on the posterior wall of the thorax just below the left scapula. After the procedure, heparin is neutralized with protamine. The dual lumen endotracheal tube is, then, replaced by a single lumen tube. Patients are extubated in the intensive care unit.

Transesophageal echocardiography is routinely used during surgery in all patients. ${ }^{[32,33]}$ Therefore, 


\begin{tabular}{l} 
Table 4 \\
$\qquad$ Surgical steps in robotic coronary revascularization \\
Surgical steps \\
\hline General anesthesia with single lung ventilation \\
Skin pads for defibrillation \\
Right 30 degree-supine position, left arm positioning \\
Port placement for robotic instruments \\
Docking procedure \\
Electrocautery for internal thoracic artery harvesting (15-20 W) \\
Carbon dioxide insufflation (3-6 lt/min, 8-12 mmHg pressure) \\
Harvesting of the left or right internal thoracic artery in a semi- or full-skeletonized fashion \\
Systemic heparinization \\
Mini-thoracotomy, coronary artery exposure, anastomosis for a MIDCAB procedure \\
No thoracotomy, pericardiotomy, endoscopic coronary artery exposure and anastomosis for a TECAB procedure \\
\hline MIDCAB: Minimally invasive direct coronary artery bypass; TECAB: Totally endoscopic coronary artery bypass.
\end{tabular}

the knowledge and experience on echocardiography of the cardiac anesthesiologist is extremely important. Since the operation is performed with total endoscopy or mini-thoracotomy, the status of cardiac functions can be easily monitored by echocardiography. The volume and inotropic support during the procedure ensures the optimal evaluation of the heart. In addition, cerebral near-infrared spectroscopy is quite useful in robotic surgery. Using this tool, we can detect the alterations in hemodynamic parameters, intravascular volume requirement, hematocrit levels, and oxygen saturation level.

\section{SURGICAL STEPS}

After general anesthesia is delivered, the patient is placed in the supine position $30^{\circ}$ to the right to remove the ITA (Table 4, Figure 2). The left thorax is elevated with a support placed beneath the scapula, the left arm lies sideways, and patient's dorsum is thrown back to give a slightly fowler position. The surgical field is prepared and covered with sterility. After this stage, the ports are placed for the left ITA harvesting. If the MIDCAB procedure is to be applied, left ITA is transected endoscopically after systemic heparinization, mini-bulldog clamp or mini-clips are used for hemostasis. The bleeding control of the chest wall is performed. The procedure is continued with mini-thoracotomy from the left fourth intercostal space. For total endoscopic $\mathrm{CABG}$, the intervention is performed by opening the pericardium, followed by harvesting of the ITA.

Robotic CABG can be performed with off-pump or on-pump techniques. Therefore, perfusion support is important during both applications. External cardiac stabilization is important when using the off-pump technique. During anastomosis, air insufflation systems are used at low levels using room air or carbon dioxide. The main goal is to adjust the minimum effective level and it is known that excessive use of insufflation causes endothelial damage. In addition, the use of intra-coronary shunt preferably varies. In this case, the patient should be kept in normothermic degrees and the activated coagulation time should be kept between 150 and 200 sec. Using the on-pump technique, the MIDCAB or TECAB procedures can

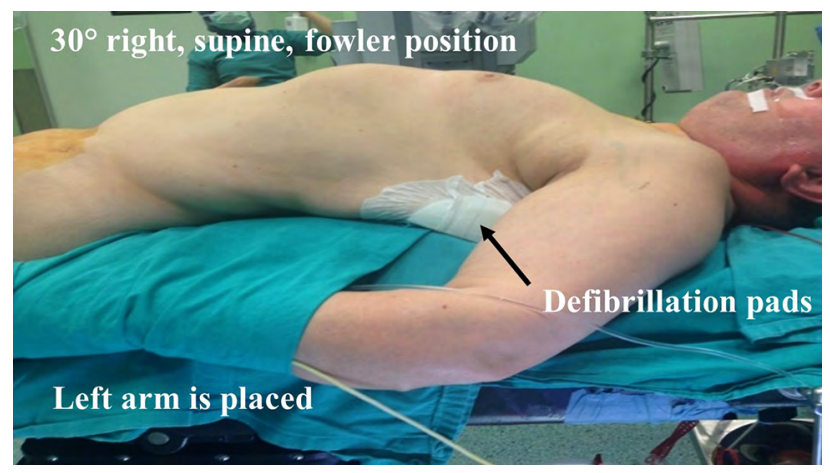

Figure 2. Position of the patient for robotic coronary revascularization. 
be performed with or without cardiac arrest under peripheral CPB. The femoral tract is safely used in cases requiring peripheric cannulation and $\mathrm{CPB} .{ }^{[34]}$

\section{PLACEMENT OF ROBOTIC PORTS}

The robotic system we use today is da Vinci $\mathrm{Si}$ HD (Intuitive Surgical, Inc., Sunnyvale, CA, USA) endoscopic surgery system. The ports can be placed differently (Figure 3). With the left thoracic approach, the left lung is deflated, and the thorax is monitored for possible adhesions with the camera port. This port is usually placed in the junction of the fourth intercostal space and anterior axillary line. Depending on the position of the patient, it can be shifted slightly to the medial or lateral position. The anatomy of the thorax is determinant for the position. The right arm instruments are placed through a port at the third intercostal space intersecting the anterior axillary line. In the same way, the left arm instruments are placed through a port in the fourth or fifth intercostal space intersecting the anterior axillary line. Approximately a 4- to 6-cm distance between these three ports allows the system to operate without any collision. In cases with elevated diaphragm, the surgical appearance and the operability of the system can be relieved by a traction suture, which will be placed on the diaphragm base. In total endoscopic CABG cases, the epicardial stabilizer is taken from the anteromedial of the left arm port into the thorax from the fifth intercostal space. Instruments commonly used for porting robotic arms include Debakey forceps, needle holder, mini-clip applicator, and electrocautery spatula. Surgical stages are achieved through the synchronized operation of the console and the bedside surgeon. The experience in endoscopic procedures and surgical knowledge of the bedside surgeon facilitates the operation.

After placement of the ports, the robotic patient side unit is docked. The electrocautery should be preferably used at a power of $20 \mathrm{~W}$. The use of higher power cautery causes more smoke in the thoracic cavity which impairs the endoscopic vision. In addition, excessive electrocautery leads to bleeding problems and hemostasis difficulties. It should not be forgotten that this robotic surgery is totally endoscopic and, in case of bleeding, gauze or serum washing cannot be taken from outside. During surgery, there are only instruments in the thorax and there is no one to assist you. This requires the surgeon to be more careful and experienced in robotic procedures.
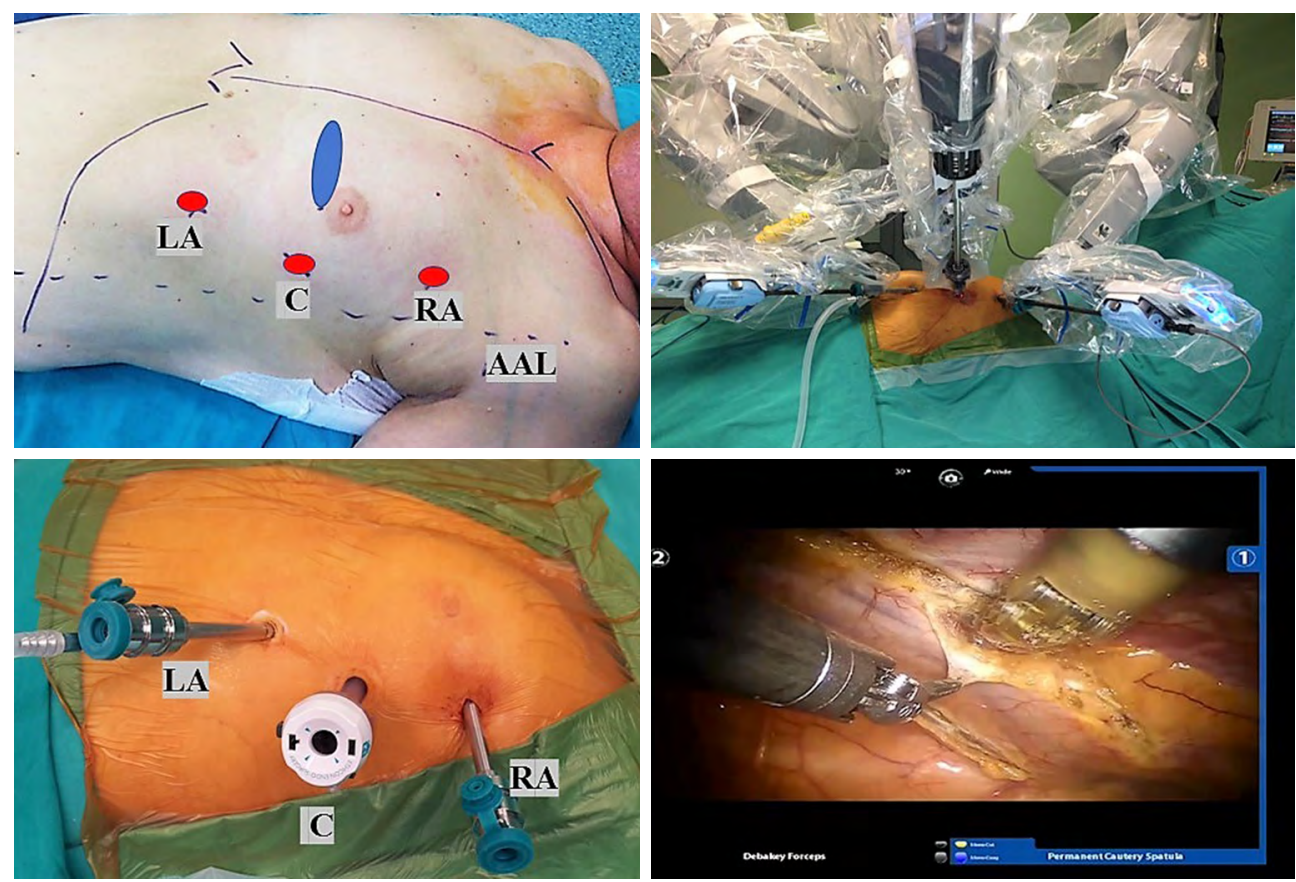

Figure 3. Port placement, docking, and harvesting of the left internal thoracic artery.

LA: Left arm; C: Camera; RA: Right arm; AAL: Anterior axillary line. 


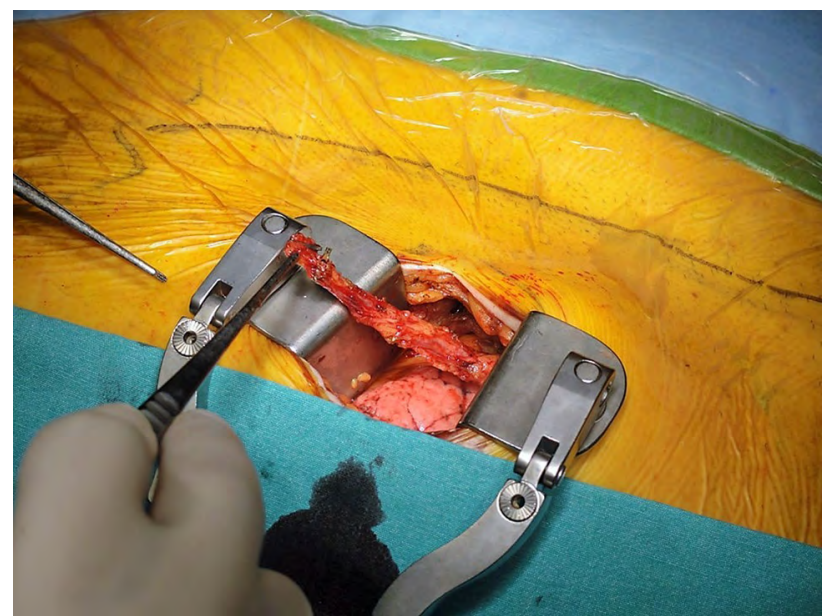

Figure 4. An intraoperative view showing the ideal length of the left internal thoracic artery and anterior mini-thoracotomy.

\section{HARVESTING OF INTERNAL THORACIC ARTERY}

In robotic surgery, ITA can technically be removed in three ways: pediculated, semi-skeletonized, or full-skeletonized (Figure 4). Cautery spatulas, mini-forceps, and mini-clamps are often used to remove the ITA robotically. Although each technique has own advantages and disadvantages, endothelial integrity can be protected with all three techniques. However, semi-skeletonizing and full-skeletonizing removal techniques highly depend on the surgeon's experience. In these techniques, the endothoracic fascia is first separated from the ITA. For full-skeletonized removal of ITA, the surgeon should avoid any traction on the vessel. There is no sensory feedback in robotic systems; therefore, traction depends on the experience and hand manipulations of the surgeon. In addition, atraumatic ITA harvesting requires the use of robotic mini-clips and angled precise Pott's scissors. When the equipment is not available, it may be advisable not to use semi- and full-skeletonized ITA removal techniques. By this way, ITA can be obtained in the ideal length and flow.

Another important issue is the technique of removing the pedicled ITA. Although adequate ITA length can be achieved in patients with a long sternum, this technique may cause ITA shortness in most patients. A short ITA anastomosis to the coronary arteries may cause traction, bleeding, myocardial ischemia, and mortality in the postoperative period.
Avoiding pedicled ITA harvesting is helpful to prevent fatal complications.

If both ITAs are to be harvested, first the right ITA should be harvested and, then, the left ITA should be prepared endoscopically. During the procedure, thorax is washed by carbon dioxide insufflation $(3-6 \mathrm{lt} / \mathrm{min}$, 8-12 $\mathrm{mmHg}$ pressure). At the end of the procedure, a chest tube or silicone drainage tube may be placed in the chest cavity, if applicable. The skin is closed with interrupted sutures using sharp 4/0 prolene stitches.

\section{MIDCAB PROCEDURE}

Several studies in the literature have demonstrated the long-term efficacy of the MIDCAB procedure. This procedure is a safe alternative to off-pump sternotomy operations. ${ }^{[8]}$ In long-term follow-up, graft patency has shown comparable results to normal operations. ${ }^{[8,16]}$ Robotic instruments and ports are removed after the isolated left ITA or bilateral ITA is removed and transected. Left anterior mini-thoracotomy is performed along the fourth intercostal space starting from the lateral side of the sternum with 5 to $10 \mathrm{~cm}$ in length. The thoracic cavity is explored with the retractors used in minimally invasive surgery. Left ITA is assessed for free flow, size, and quality before the anastomosis. The distal side is prepared for the anastomosis. The pericardium opens anteromedially in the direction of the apex-pulmonary hilus, parallel to the LAD artery. Thus, the left ITA enters the pericardial space without any kink or torsion. Once the pericardiostomy is performed, the LAD is revealed with the help of sutures. External vacuum-assisted or pressure-assisted systems can be used for LAD stabilization (Figure 5). Coronary anastomosis is done using the off-pump technique. Air or carbon dioxide insufflation may be used during the procedure. The use of shunt during the anastomosis is based on the surgeon's preference.

An ideal left-sided ITA-LAD anastomosis can be summarized as an anastomosis in which endothelial injury-free manipulations are used, whereas ITA is not stretched and shows good filling (Figure 6 and 7). The left ITA should be left at the end of surgery between the mediastinum and the left lung, anterior to pulmonary hilus, ensuring that there is no traction. In case of suspicious vascular tension, it should be kept in mind that postoperative catastrophes may occur. In addition, in patients with a poor coronary artery vascular quality or low left ventricular function, 

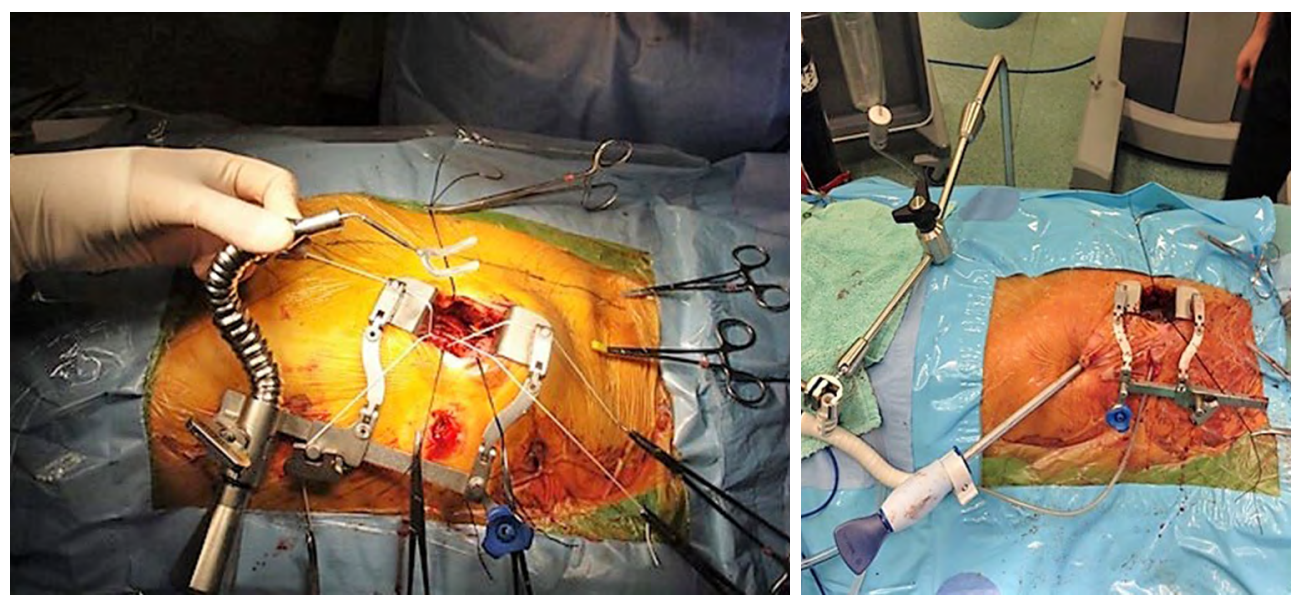

Figure 5. Surgical set-up for off-pump coronary revascularization through anterior mini-thoracotomy using mechanical (left view) and vacuum-assisted (right view) cardiac stabilizers.

MIDCAB under CPB may be preferred to warrant patient safety.

\section{TECAB PROCEDURE}

For the first time, total endoscopic off-pump CABG surgery was performed by Watanabe et al. ${ }^{[1]}$ Loulmet et al. ${ }^{[2]}$ reported the first robotic on-pump TECAB procedure with cardiac arrest in 1998. The first off-pump TECAB operation with endoscopic stabilizers was performed by Falk et al. in $2000 .{ }^{[3]}$ Due to these difficulties, TECAB operations, which need a high degree of surgical experience and technical skills, have not become popular since then.

Robotic instruments are inserted into the thorax after placement of the ports. Bilateral or

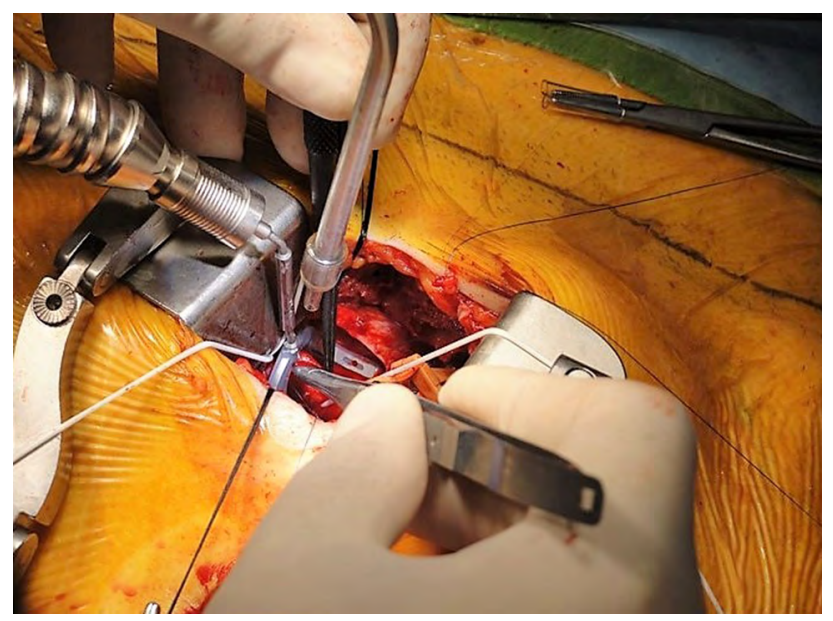

Figure 6. Off-pump coronary revascularization. left ITA is harvested from the anterior chest wall by total endoscopic robotic surgery. Thoracotomy is not performed. Once the left ITA is prepared endoscopically and divided, the pericardium is opened and the target coronary artery is exposed. Coronary anastomosis can be performed using the on-pump or off-pump technique. After epicardial stabilization, the coronary artery can be rotated with special mini-loops, where applicable, from the proximal or distal side. Coronary artery is prepared for anastomosis by arteriotomy with robotic coronary scalpel and potts scissors. Coronary anastomosis can be made with ready-made suture materials, such as U-clips (Medtronic, Minneapolis, MN, USA) or prolene sutures. Continuous or individual suturing techniques are optional. At this stage, blood drops

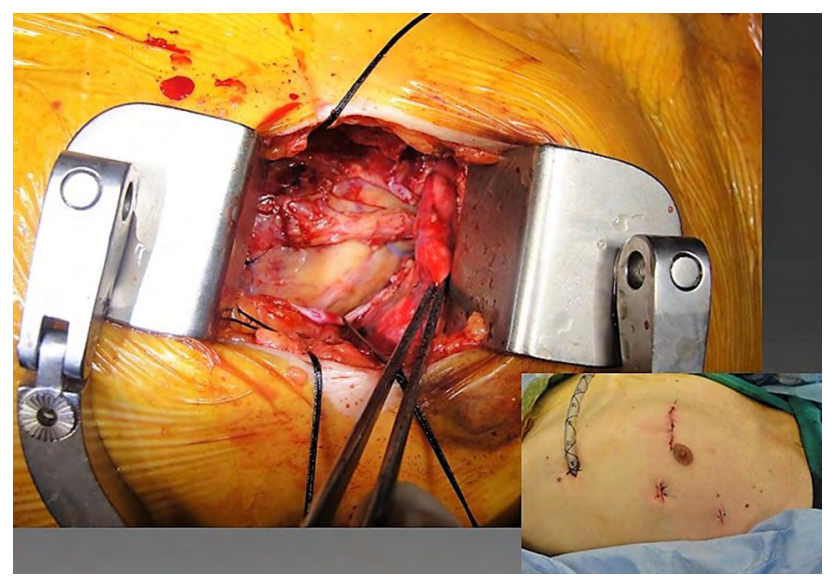

Figure 7. Final view after anastomosis of the left internal thoracic artery with the left anterior descending artery. 
which accumulate in the surgical field are washed with a liquid-injection system mounted on the epicardial stabilization apparatus and a clear view is provided. Hypothermia can be maintained according to the preference of the surgeon in on-pump procedures. Endo-aortic balloon occlusion or transthoracic aortic clamps can be also used, if cardiac arrest is to be performed. A special epicardial vacuum stabilizer is used during coronary anastomoses.

\section{MIDCAB AND TECAB IN AN ON-PUMP} BEATING HEART

The on-pump technique can be used in MIDCAB and TECAB procedures. Hemodynamic stabilization can be performed by evacuating the heart on-pump during the MIDCAB operation. This is the preferred approach in multivessel disease or in cases with a poor vascular structure. A more secure anastomosis is provided for the patient safety during bypass.

\section{MIDCAB AND TECAB WITH ON-PUMP CARDIAC ARREST}

Some surgeons may prefer anastomosing on the arrested heart using this technique. This technique is preferred to perform a safe operation and to increase the anastomosis quality, particularly in patients with relatively thin and unstructured vessels. Antegrade blood cardioplegia can be used as a cardioplegia agent and Custodiol-HTK (histidine-tryptophan-ketoglutarate) cardioplegia solution can be used to provide cardiac arrest, as well. This liquid component, which is an organ preservation solution, can be safely delivered every $120 \mathrm{~min}$ to achieve cardiac arrest. ${ }^{[13,35]}$ Endoaortic balloon occlusion catheters are the easiest and reliable methods in TECAB procedures. However, transesophageal echocardiography and perfusionist support during operation and occlusion are extremely important.

\section{HYBRID CORONARY REVASCULARIZATION}

The main objective of hybrid treatment approaches is to reduce surgical morbidity and mortality using minimally invasive surgical techniques and catheterization interventions. ${ }^{[9,11]}$ Postoperative complications in the surgical treatment of cardiovascular diseases are related to the type of operation, timing, and associated morbidities of the patient before surgery. Cardiopulmonary bypass methods used during cardiovascular surgery may also cause adverse effects after surgery. ${ }^{[36]}$ Therefore, minimally invasive techniques with lesser systemic traumas and the simultaneous application of percutaneous catheterization methods have become more popular in recent years. Hybrid interventions used in cardiovascular diseases include hybrid CABG (minimally invasive) and percutaneous coronary interventions (PCI).

Hybrid CABG/PCI treatment is a combination of traditional surgical methods and PCI in a broad sense. Using this approach, early or elective interventions can be planned in patients with indications for coronary artery revascularization. Hybrid CABG/ $\mathrm{PCI}$ can be used in high-risk patients for conventional surgical treatment. ${ }^{[9,11,37]}$ The LAD revascularization with the left ITA is performed surgically in these patients. Complementary non-LAD coronary artery revascularization is performed with PCI. Indications for hybrid CABG/PCI include proximal LAD stenosis and presence of a non-LAD lesion (right coronary or circumflex artery) suitable for PCI. Non-LAD non-surgical coronary lesions (such as the proximal circumflex artery lesion in the atrioventricular groove) which are unsuitable for surgery, but suitable for PCI, can be preferred in hybrid methods. Hybrid coronary interventions can be performed by MIDCAB or TECAB techniques. ${ }^{[9,11]}$

In conclusion, robotic CABG operations are currently among the minimally invasive cardiac surgical interventions. These interventions offer important advantages, such as appropriate early rehabilitation of the disease, less blood product use, less pain, favorable cosmetic outcomes, and early return to daily life. Nevertheless, robotic surgical systems have significant disadvantages, such as high cost and limited availability. In the future, we believe that alternative robotic systems would be invented and become widespread, and the beneficial advantages would get ahead of the current disadvantages.

\section{Declaration of conflicting interests}

The author declared no conflicts of interest with respect to the authorship and/or publication of this article.

\section{Funding}

The author received no financial support for the research and/or authorship of this article. 


\section{REFERENCES}

1. Watanabe G, Takahashi M, Misaki T, Kotoh K, Doi Y. Beating-heart endoscopic coronary artery surgery. Lancet 1999;354:2131-2.

2. Loulmet D, Carpentier A, d'Attellis N, Berrebi A, Cardon C, Ponzio $\mathrm{O}$, et al. Endoscopic coronary artery bypass grafting with the aid of robotic assisted instruments. J Thorac Cardiovasc Surg 1999;118:4-10.

3. Falk V, Diegeler A, Walther T, Banusch J, Brucerius J, Raumans J, et al. Total endoscopic computer enhanced coronary artery bypass grafting. Eur J Cardiothorac Surg 2000;17:38-45.

4. Carpentier A, Loulmet D, Aupècle B, Kieffer JP, Tournay D, Guibourt P, et al. Computer assisted open heart surgery. First case operated on with success. C R Acad Sci III 1998;321(5):437-42. [Abstract]

5. Mohr FW, Falk V, Diegeler A, Autschback R. Computerenhanced coronary artery bypass surgery. J Thorac Cardiovasc Surg 1999;117:1212-4.

6. Benetti FJ, Ballester C. Use of thoracoscopy and a minimal thoracotomy, in mammary-coronary bypass to left anterior descending artery, without extracorporeal circulation. Experience in 2 cases J Cardiovasc Surg (Torino) 1995;36:159-61.

7. Angelini GD, Wilde P, Salerno TA, Bosco G, Calafiore AM. Integrated left small thoracotomy and angioplasty for multivessel coronary artery revascularisation. Lancet 1996;347:757-8.

8. Bonatti J, Ramahi J, Hasan F, Edris A, Bartel T, Nair R, et al. Long-term results after robotically assisted coronary bypass surgery. Ann Cardiothorac Surg 2016;5:556-562.

9. Bonatti JO, Zimrin D, Lehr EJ, Vesely M, Kon ZN, Wehman $\mathrm{B}$, et al. Hybrid coronary revascularization using robotic totally endoscopic surgery: perioperative outcomes and 5-year results. Ann Thorac Surg 2012;94:1920-6.

10. Ishikawa N, Watanabe G. Robot-assisted cardiac surgery. Ann Thorac Cardiovasc Surg 2015;21:322-8.

11. Onan B, Bakir I. Kardiyovasküler hastalıklarda hibrit girişimler. Turkiye Klinikleri J Cardiovasc Surg-Special Topics 2015;7:32-7.

12. Onan B, Bakir I. Robotik atriyal septal defekt operasyonları. Türkiye Klinikleri J Cardiovasc Surg-Special Topics 2015;7:24-31.

13. Onan B, Bakir I. Robotik mitral ve triküspit kapak operasyonları. Turkiye Klinikleri J Cardiovasc Surg-Special Topics 2015;7:16-23.

14. Kwoh YS, Hou J, Jonckheere EA, Hayati S. A robot with improved absolute positioning accuracy for CT guided stereotactic brain surgery. IEEE Trans Biomed Eng 1988;35:153-60.

15. McConnell PI, Schneeberger EW, Michler RE. History and. development of robotic cardiac surgery. Problems in General. Surgery 2003;20:20-30.

16. Ezelsoy M, Caynak B, Bayram M, Oral K, Bayramoglu $\mathrm{Z}$, Sagbas E, et al. The comparison between minimally invasive coronary bypass grafting surgery and conventional bypass grafting surgery in proximal LAD lesion. Heart Surg Forum 2015;18:42-6.

17. Caynak B, Sagbas E, Onan B, Onan IS, Sanisoglu I, Akpinar B. Robotically enhanced coronary artery bypass grafting: the feasibility and clinical outcome of 196 procedures. Int J Med Robot 2009;5:170-7.

18. Sagbas E, Akpinar B, Sanisoglu I, Caynak B, Guden M, Ozbek U, et al. Robotics in cardiac surgery: the Istanbul experience. Int J Med Robot 2006;2:179-87.

19. Senay S, Gullu AU, Alhan C. Robotic mitral valve replacement for rheumatic mitral disease. Ann Cardiothorac Surg 2017;6:64-6.

20. Senay S, Gullu AU, Kocyigit M, Degirmencioglu A, Kilic L, Karabulut H, et al. Robotic mitral valve replacement for severe rheumatic mitral disease: perioperative technique, outcomes, and early results. Innovations (Phila) 2014;9:292-6.

21. Onan B, Aydın Ü, Kahraman Z, Bakır İ. Robotic surgery for atrial septal defect closure in a case of Kabuki syndrome. Turk Kardiyol Dern Ars 2017;45:77-81.

22. Onan B, Aydin U, Kahraman Z, Erkanli K, Bakir I. Robot-Assisted Mitral Valve Repair With Posterior Leaflet Extension for Rheumatic Disease. Innovations (Phila) 2017;12:60-3.

23. Onan B, Aydin U, Turkvatan A, Bakir I. Robot-assisted repair of right partial anomalous pulmonary venous return. J Card Surg 2016;31:394-7.

24. Onan B, Aydin U, Kahraman Z, Bakir I. Robotic atrial septal defect closure and tricuspid annuloplasty in a case of situs inversus totalis with dextrocardia. J Robot Surg 2017;11:87-90.

25. Onan B, Bakir I. Robotic Mitral Valve Replacement in Pectus Excavatum. J Card Surg 2016;31:306-8.

26. İyigün T, Kaya M, Gülbeyaz SÖ, Fıstıkçı N, Uyanık G, Yllmaz B, et al. Patient body image, self-esteem, and cosmetic results of minimally invasive robotic cardiac surgery. Int J Surg 2017;39:88-94.

27. Onan B, Bakir I. Minimal invaziv kardiyak cerrahi için hasta seçimi ve klinik protokoller. Turkiye Klinikleri J Cardiovasc Surg-Special Topics 2015;7:1-6.

28. Modi P, Hassan A, Chitwood WR Jr. Minimally invasive mitral valve surgery: a systematic review and meta-analysis. Eur J Cardiothorac Surg 2008;34:943-52.

29. Gammie JS, Zhao Y, Peterson ED, O'Brien SM, Rankin JS, Griffith BP. J. Maxwell Chamberlain Memorial Paper for adult cardiac surgery. Less-invasive mitral valve operations: trends and outcomes from the Society of Thoracic Surgeons Adult Cardiac Surgery Database. Ann Thorac Surg 2010;90:1401-8.

30. Yamada T, Ochiai R, Takeda J, Shin H, Yozu R. Comparison of early postoperative quality of life in minimally invasive versus conventional valve surgery. J Anesth 2003;17:171-6.

31. Walther T, Falk V, Metz S, Diegeler A, Battellini R, Autschbach R, et al. Pain and quality of life after minimally invasive versus conventional cardiac surgery. Ann Thorac Surg 1999;67:1643-7. 
32. Kahraman MZ, Bakir I. Minimal invaziv cerrahide anestezi yaklaşımları. Turkiye Klinikleri J Cardiovasc Surg-Special Topics 2015;7:7-9.

33. Koçyiğit M, Akpek EA, Tetik Ö, Şenay Ş, Alhan C. Robotik yardımlı ve robotik kardiyak cerrahide anestezi deneyimlerimiz. Turk Gogus Kalp Dama 2013;21:972-7.

34. Aydın Ü, Kadiroğulları E, Bakir I. Minimal invaziv kardiyak cerrahide kardiyopulmoner baypas ve perfüzyon teknikleri. Turkiye Klinikleri J Cardiovasc Surg-Special Topics 2015;7:10-5.

35. Hummel BW, Buss RW, DiGiorgi PL, Laviano BN,
Yaeger NA, Lucas ML, et al. Myocardial Protection and Financial Considerations of Custodiol Cardioplegia in Minimally Invasive and Open Valve Surgery. Innovations (Phila) 2016;11:420-4.

36. Kirklin JK, Westaby S, Blackstone EH, Kirklin JW, Chenoweth DE, Pacifico AD. Complement and the damaging effects of cardiopulmonary bypass. J Thorac Cardiovasc Surg 1983;86:845-57.

37. Us MH, Basaran M, Yilmaz M, Yaymaci B, Ulusoy E, Sanioglu S, et al. Hybrid coronary revascularization in high-risk patients. Tex Heart Inst J 2006;33:458-62. 